\title{
A INFLUÊNCIA DO EFEITO PRIMING E ESTIMULAÇÃO COGNITIVA PARA A LEITURA ORAL DE TEXTOS EM IDOSOS COM DOENÇA DE ALZHEIMER
}

\author{
THE INFLUENCE OF COGNITIVE STIMULATION AND PRIMING EFFECT FOR ORAL \\ READING OF TEXTS IN ELDERLY WITH ALZHEIMER'S DISEASE
}

Priscilla Chantal Duarte Silva

Universidade Federal de Itajubá

\begin{abstract}
RESUMO: A leitura, assim como outras habilidades cognitivas, requer boas condições de funcionamento da mente e do cérebro humano além de uma interconexão entre as funções neuronais. Nesse contexto, a memória tem uma grande relevância para a habilidade de leitura, uma vez que a compreensão é um requisito importante para a efetivação do ato de ler. Nesse sentido, se compreendemos o conteúdo da leitura, certamente memorizamos e processamos a informação proveniente dos sentidos. Afinal, a cada momento, informações chegam aos nossos sentidos e, no caso da leitura, não é diferente. É fato que o cérebro precisa extrair sentido dos conteúdos do que chega às vias sensoriais e utilizar o conhecimento já presente para extrair sentido da informação recebida. Vejamos, então, que a memória se encontra nesse intermédio entre "reter" de alguma forma o que vem dos sentidos, buscar o que já tem para e, então, extrair uma conclusão. Nesse processo, uma operação de comparação entre o que chega e o que já é conhecido parece acontecer, haja vista nossa capacidade de reconhecer que algo já nos é conhecido. A comparação, portanto, parece um fenômeno natural pelo fato de termos a capacidade de nos lembrar e reconhecer a informação como já conhecida. Do contrário, a memória seria inútil e não reconheceríamos nada. Sendo assim, ao lermos algo, estamos lidando com as atuações da memória. No presente estudo, observamos, a partir de uma pesquisa de campo do tipo qualitativa e de cunho exploratório que, de um modo geral, a maior dificuldade pelos sujeitos com DA é na produção de sentido, daquilo que leem. Sendo assim, procuramos entender a possível relação de influência do comprometimento da memória na leitura compreensiva. Para isso, os critérios foram: analisar a produção de sentido de textos curtos e longos, simples e complexos, averiguando os mecanismos de recall, interpretação em leitura oral e compreensão auditiva, influência do efeito priming e estímulo no processo de interação. A leitura mecânica foi observada em quase todos os estágios da DA, regredindo-se a cada fase. Dessa forma, procuramos analisar e demonstrar essas diferenças em cada um dos estágios. Solicitamos, então, aos idosos com e sem DA que fizessem uma leitura oral a fim de verificarmos a compreensão desses sujeitos e entendermos o funcionamento do efeito priming para o processo de leitura e compreensão de textos. Participaram do estudo 57 idosos com doença de Alzheimer, divididos por grupos de mesma escolaridade e condições socioeconômicas para melhor isonomia do grupo pesquisado. Os resultados apontaram uma grande influência do efeito priming para a memorização de trechos e partes lexicais durante a leitura oral de idosos com doença de Alzheimer, o que auxiliava na efetivação da leitura. Contudo, restrito e condicionado às etapas mais avançadas da doença.
\end{abstract}

PALAVRAS-CHAVE: memória, leitura, cognição, primazia da palavra, doença de Alzheimer 


\section{Revista do SELL \\ v. $4, n^{\circ} .1$ \\ ISSN: $1983-3873$}

ABSTRACT: Reading, like other cognitive skills requires good working of the mind and the human brain beyond an interconnection between neuronal functions. In this context, the memory has a large bearing on the ability to read, once that understanding is an important prerequisite for the realization of the act of reading. In this sense, if we understand the contents of reading, certainly memorize and process information from the senses. After all, every time information come to our senses and, in the case of reading, is no different. It is a fact that the brain needs to make sense of the content that reaches the sensory pathways and use this knowledge now to make sense of the information received. Let us see, then, that memory is intermediate between that "retain" somehow what comes from the senses, look what you have to then draw a conclusion. In this process, a comparison operation between arriving and what seems to happen is already known, given our ability to recognize that something is already known on. The comparison therefore seems a natural phenomenon because we have the ability to remember and recognize the information as already known. Otherwise, the memory would be useless and not recognize anything. Therefore, when we read something, we're dealing with the actions of memory. In the present study, we observed, from a field survey, a qualitative exploratory and that, generally, the more difficult by the subjects with $A D$ is the production of meaning from what they read. So try to understand the possible relationship of influence of memory impairment in reading comprehension. For this, the criteria were: to analyze the production of meaning of short texts and long, simple and complex,

KEYWORDS: memory, reading, cognition, priming, Alzheimer's disease

\section{INTRODUÇÃO}

A Doença de Alzheimer, ou simplesmente DA, tem esse nome por causa do Dr. Alois Alzheimer, neurologista alemão (1864-1915), que em 1906, observou alterações no tecido cerebral de uma mulher que consideravam ter morrido por uma doença mental rara. Como destacam Cayton et al. (2000, p. 16),"demência é um termo usado para descrever várias alterações cerebrais que resultam em uma severa e progressiva perda da memória. A doença de Alzheimer (DA) é o tipo mais comum [...]". O termo demência vem do latim, dementia, de + mentia, que significa ausência de mente. Em linhas gerais, a DA faz com que as pessoas percam gradativamente sua orientação no tempo e no espaço. Um sintoma maior é o de que esquecem o que acabaram de dizer ou fazer, embora sua memória de eventos passados possa parecer nítida, deixam de se comunicar, algumas vezes passam a ter comportamentos severos. O déficit de memória, sobretudo, a de curta duração ou curto-termo já é uma característica consolidada da DA, enquanto os danos na memória de longo-termo aparecem tardiamente. A doença é divida em estágios, nos quais outros sintomas são observados. Entre esses, podemos destacar as dificuldades nas tarefas diárias, esquecimento e dificuldades de comunicação com encadeamento lógico. 


\section{Revista do SELL}

v. $4, n^{\circ} .1$

ISSN: $1983-3873$

A dificuldade com a linguagem retrata a influência da memória nas mais variadas funções cognitivas e, principalmente, na linguagem e na leitura. Sendo assim, foi possível verificar que ao falarmos dessa relação, não há como não levar em conta o lapso do esquecimento como a ausência momentânea de nomes, de um discurso ou de imagens conhecidas previamente. Quem nunca se deparou com o efeito ponta da língua, em que a memória parece estar preservada de alguma forma milésimos de segundos antes de pronunciarmos algo como "eu sei isso"; "acabei de lembrar"; "eu sabia o nome disso"; "está na ponta da língua", mas por algum motivo não pode ser evocado. O esquecimento é uma experiência desagradável e todos compreendem que a linguagem, nesses casos, parece se ocultar. Contudo, ao enunciar essas formulações, não há como negar que, ao dizê-las, o sujeito acaba por utilizar a linguagem. Não se trata aqui de dizer que se têm duas linguagens nesses contextos, mas de haver falhas de memória que afetam, em microtempos, a linguagem.

No processo de rememoração, afirma Corrêa (2010, p.237), "os traços mnésicos são procurados ativamente, seja consciente ou inconsciente". O resgate pode se dar na forma de reconhecimento e evocação. Enquanto a primeira consiste em perceber uma informação como memorizada anteriormente, a segunda busca uma lembrança por meio de um índice e parece se instalar na busca de uma lembrança. $O$ índice se refere a uma espécie de dica que serve como gatilho para a reconstrução do passado. Assim, na percepção de um item, em geral, buscamo-lo por meio de algum outro objeto que serve como indicação de uma espécie de caminho até o objeto alvo da lembrança.

No que concerne ao processo de recall, o efeito priming ou simplesmente primazia da palavra - termo que diz respeito à capacidade ou facilidade de memorizar os primeiros elementos de uma lista de estímulos, isto é, quando a tarefa é memorizar uma lista de palavras ou termos; tem o papel de ativar memórias como uma espécie de desencadeador. Nas palavras de Butler e Berry (2004), a repetição do tipo priming é a facilitação ou influência no processamento de um estímulo como uma função de um recente encontro com esse estímulo, um exemplo da memória implícita. Esse tipo de memória refere-se à tarefa da memória e não realizar qualquer esforço consciente para lembrar (FLEISCHMAN, 2008).

Para Izquierdo (2002), esse tipo de memória é ativado por meio de dicas, seja por fragmentos de palavras, de imagens e de gestos, no sentido de completar uma palavra, por exemplo, a partir da evocação das primeiras sílabas. Trata-se de um fenônemo que 


\section{Revista do SELL \\ v. $4, n^{\circ} .1$ \\ ISSN: $1983-3873$}

envolve áreas associativas, por essa razão o autor sugere que as memórias são formadas em paralelo. Nesse aspecto, Hudmon (2006) aponta que o processo da primazia consiste em um tipo de memória procedural, a partir de fragmentos das palavras. Em experimentos, o autor alega que o sujeito analisado é capaz de lembrar algumas palavras de uma lista, por exemplo, por meio de um estímulo dado a partir de alguma sílaba da palavra, principalmente a primeira. Com isso, verificamos também que, mesmo diante de uma perda de memória, como nos casos de DA, o sujeito é capaz de lembrar por meio desse processo de primazia.

Em estágios mais avançados da DA, no entanto, o efeito da primazia tende também a regredir, diminuindo consideravelmente a eficácia de recordação, porém sem se exaurir totalmente. Nosso questionamento centra-se, então, na hipótese de que a linguagem faria parte também da memória procedural por algum aspecto de ordem mecânica, o que manteria a primazia da palavra, bem como a leitura mecânica, considerando a pronúncia, a evocação das palavras, porém sem a presença de um cunho semântico e de consciência fonológica. No presente estudo, verificamos como esse efeito atua como estimulação cognitiva para a leitura de idosos com DA. Para isso, valemo-nos de uma pesquisa de campo envolvendo 57 idosos com DA, com o objetivo de averiguar de que forma o efeito priming pode atuar como uma estimulação cognitiva na leitura, haja vista seu papel de trazer à memória conteúdos por meio de dicas.

\section{ASPECTOS COGNITIVOS DA LEITURA E A DOENÇA DE ALZHEIMER}

Segundo Fischer (2006), desde os primórdios, ler significava declamar, isto é, envolvia a habilidade de fala, enquanto a escrita confirmava, nos moldes de uma "memória externa", a palavra humana em pedra. Dessa forma, a escrita nada mais era que o registro da linguagem oral. Entretanto, devemos avaliar também que a leitura provém de um reconhecimento da mente em decifrar o código linguístico, no caso da escrita, dentro de um padrão sonoro da língua. Nesses termos, podemos dizer que a leitura subjaz à escrita, pois é necessário ativar na mente o código da língua para, então, atribuir-Ihe sentido. Nas palavras de Frith (1979, p. 380, tradução nossa) ${ }^{1}$, "o modo como reconhecemos as palavras escritas é primeiramente traduzi-las dentro do som para então

\footnotetext{
1 "[...] the way we recognise written words is first to translate them into sound then to treat the resulting sounds as if they we heard speech" (FRITH, 1979, P.380)
} 


\section{Revista do SELL \\ v. $4, n^{\circ} .1$ \\ ISSN: $1983-3873$}

tratar o resultado desse som como se fosse a fala que ouvimos". Em outras palavras, a leitura envolve uma espécie de tradução cognitiva do som.

Porém, devemos lembrar que a leitura não é somente oral. Na leitura silenciosa, podemos também extrair sentido ainda que não conheçamos todos os sons da língua, como no caso de uma língua estrangeira, por exemplo. Com isso, compartilhamos da idéia de Frith (1979) de que todos os tipos de leitura compartilham do mesmo processo de entendimento, no sentido de interpretar. Afinal, embora os sentidos tenham uma grande contribuição, a leitura se resume em um processo holístico semântico e não meramente a extração de sons. Como lembra Smith (2003, p.16), "ler é menos uma questão de extrair sons de letras impressas do que de dar significado a estas letras".

Para Fischer (2006, p.11), "a leitura consiste na capacidade de extrair sentido de símbolos escritos ou impressos". Esses símbolos, por sua vez, permitem que recuperemos informações da memória, pois, para que a leitura se efetive, é necessário reconhecer os símbolos num sistema auto-organizado de junção de símbolo, som e sentido. Para Fischer (2006), a leitura não é apenas a união do som ao grafema, mas também a relação com o significado.

A leitura é o produto ou o efeito de sentido ou, ainda, um processo cognitivo. No entanto, devemos pensar que, se extrair sentido de símbolos é o significado do que chamamos de leitura, quando reconhecemos e entendemos o que está representado numa imagem por meio de signos também pode ser considerado "leitura", pois muito mais que perceber o objeto, estamos atribuindo sentido ao que vemos.

Como aponta Smith (2003), leitura e aprendizado da leitura são atividades essencialmente significativas, isto é, requer entendimento, envolve um significado. Por essa razão, não são questões ou atividades passivas ou mecânicas, como se pensava na crença tradicional de que a leitura é simplesmente descodificação, na qual se reconhecem sons e letras, mas uma atividade racional, dependendo também do conhecimento prévio e das expectativas do leitor.

De acordo com Kleiman (1995), a descodificação trata-se apenas de automatismos de identificação das palavras no texto, e isso por si só não garante a compreensão. Nesse aspecto, a leitura está para além da descodificação, pois o leitor eficiente faz muito mais que isso: ele percebe as palavras de forma global e adivinha outras tantas, guiado pelo conhecimento de mundo e hipóteses de leitura. O leitor deve ser capaz, após a 


\section{Revista do SELL \\ v. $4, n^{\circ} .1$ \\ ISSN: $1983-3873$}

descodificação, de produzir sentido, ou seja, ser capaz de saber do que se trata o texto, compreender o que o autor possivelmente pretendeu.

De nada adianta descodificar, reconhecer as palavras se elas se tornam vazias de significado, isto é, se o leitor não consegue produzir sentido para aquilo que lê. No entanto, não estamos afirmando que o processo de descodificação não seja relevante, afinal, "O domínio mecânico e elementar do código responde por uma fase inicial da nossa atividade de leitura, sem ele seríamos incapazes de dar conta de processos mais elaborados que estão implicados nas etapas subsequentes", como afirma MARI, (2005, p.161), porém, não deve ser o único. Sendo assim, a leitura não pode se esgotar na visão ou na descodificação. Esta, por sua vez, "é intelectual, pois sem o intelecto jamais haveria visão, percepção ou apreensão de objetos" (SCHOPENHAUER, 2005, p. 29). Desse modo, podemos considerar a leitura, desde a descodificação, como um ato do intelecto. Afinal, ela não consiste em apenas "captar" e decifrar signos linguísticos pelo órgão da visão, mas processar esses signos de forma que os tornem significáveis.

Devemos pensar a leitura como uma atividade funcional do cérebro, ou seja, que envolve linguagem, assim como a fala e a percepção auditiva. Além disso, outros fatores também estão correlacionados, tais como: a memória, a atenção, interação, diferenças socioculturais e de aprendizagem. Na perspectiva de Freire (1984, p.11), "a leitura do mundo precede a leitura da palavra", o que implica dizer que o conhecimento de mundo também influencia a leitura e a aprendizagem desta, pois se baseia na compreensão. Da mesma forma, podemos dizer que a memória influencia a leitura, pois como é possível chegar ao final da leitura sem a atuação da memória em orientar o conteúdo do texto? Seria como mecanicamente passar os olhos e não captar o conteúdo suficiente para produzir sentido.

Não há, nessa concepção, portanto, leitura (verdadeira) sem compreensão. Se não há entendimento, o que resta é apenas movimentação ou estimulação mecânica, isto é, passar os olhos sobre as palavras, que se tornam simples objetos gráficos, ou reprodução sonora de signos linguísticos. "A leitura é vista como uma atividade construtiva e criativa, tendo quatro características distintivas e fundamentais - é objetiva, seletiva, antecipatória e baseada na compreensão [...]" (SMITH, 2003, p.17). Nessa concepção, a compreensão ou entendimento diz respeito ao que já possuímos na mente e o aprendizado àquilo que será modificado. Em outras palavras, ativamos em nossas mentes o que já conhecemos sobre tudo o que nos chega aos olhos quando lemos e aprendemos através da leitura 


\section{Revista do SELL}

v. $4, n^{\circ} .1$

ISSN: $1983-3873$

acrescentando coisas àquilo que já sabemos, ou seja, obtemos conhecimento por meio da leitura.

Não há como entender a leitura se também não reconhecemos categorias num texto. Elas consistem em convenções e compreendem ao nosso entendimento de mundo ou, como aponta Smith (2003), a base de nossa percepção do mundo, pois vemos o que o cérebro decide, o que significa a categoria na qual a informação está alocada. Para o autor, quando lemos "gato", devemos ter uma categoria para aquela palavra. Nesse sentido, podemos considerar a leitura como uma atividade cognitiva de reconhecimento e interpretação categórica. Sobre isso, o autor considera que a categorização é um mecanismo inato da mente em distinguir em igualdades e diferenças objetos ou eventos uma condição para a sobrevivência e aprendizado humano.

No que tange ao envolvimento da categorização com a leitura, vale destacar que, na DA, a leitura parece, em alguns momentos, fragmentada e desconexa da significação, de modo que os sujeitos com DA revelam uma dificuldade na interpretação do conteúdo que leem e, em outros, uma leitura meramente mecânica, o que nos leva a crer num tipo de "descategorização", no sentido de "perderem" ou trocarem a nomenclatura da categoria. Sendo assim, associamos isso à memória, uma vez que temos em nossas mentes não só a forma, mas também a significação das palavras que visualizamos numa leitura escrita, numa forma de registro de modo que ao nos depararmos com elas, uma série de agrupamentos ou "caminhos" neuronais que são ativados e reconhecidos. Na visão de Chartier (1995), esse reconhecimento se dá por uma espécie de "endereçamento" que se apoia na memória, um tipo de glossário mental, num processo de estocagem à medida que lemos.

Como a habilidade de leitura também tem seus reflexos na memória, acreditamos que esse seja o ponto-chave da questão, uma vez que, em alguns momentos, a leitura acontece, justamente quando o recall parece estar presente. Sob esse aspecto, a hipótese é a de que a memória parece sofrer oscilação, nesses casos, ou seja, alternando presença com ausência, de modo que nas falhas a leitura não se efetiva. Devemos lembrar, no entanto, que perceber esses movimentos não é tarefa fácil, pois os limiares da memória ainda são fluidos.

Chartier (1995, p. 62) alega que, em geral, "é muito raro que um leitor não compreenda nada, mas, mesmo que ele retenha informações esparsas, pode muito bem se dar conta de que não compreendeu verdadeiramente". Todavia, segundo a autora, não 


\section{Revista do SELL}

v. $4, n^{\circ} .1$

ISSN: $1983-3873$

se pode dizer que não compreendeu nada, o que nos leva a crer que alguma informação permanece.

Nesse sentido, nosso desafio foi averiguar o que de fato se mantinha. A partir dessa concepção, verificamos, em nosso estudo, nos casos de DA, nos mais variados estágios, que certamente alguma coisa permanece, ainda que o restante da informação caminhe para outro rumo e não se consiga estabelecer a compreensão efetiva da leitura. Sendo assim, verificamos que, durante a leitura, de um texto ou de uma oração, por exemplo, alguma ou algumas poucas palavras são usadas pelo portador de DA para nos informar o que compreendeu do texto lido. Contudo, a compreensão vai se reduzindo de acordo com o agravamento da doença, nos seus respectivos estágios.

Outro fator cognitivo relacionado à leitura é a capacidade de representar e de reconhecer familiaridades de nossas experiências. Nesse sentido, no ato de ler, é possível extrair sentido tanto do conteúdo que reconhecemos, ou seja, já nos é conhecido, quanto de novas experiências - conteúdos novos. Em outras palavras, ao ler não só ativamos nossa memória, mas também a renovamos continuamente. Como afirma Smith (2003), essas representações são chamadas de esquemas e, por meio delas, podemos reconhecer e extrair sentido dessas experiências pelo fato de termos, em nossas estruturas cognitivas, esquemas de imagens semelhantes, das quais podemos extrair o sentido por analogia.

No que concerne à leitura dos idosos com DA, é possível averiguar que, muitas vezes, é possível presenciar uma leitura da esquerda para a direita no início do texto, seguida de uma desorientação espacial do corpo do texto, ao longo da leitura, dependendo do estágio da doença. Normalmente, demonstram falta de atenção e não fixação no texto, parecendo não seguir as linhas. Verificamos que, quanto maior o nível da DA, maior a dispersão e maior o comprometimento da leitura, no que tange à compreensão. Em geral, o processo mecânico da leitura na nossa tradição é feito dessa forma, mas o mesmo não pode ser dito da compreensão do texto, haja vista que não podemos definir uma sequenciação ou regra para a compreensão textual.

Já nos primeiros estágios, é possível observar algumas trocas de letras, palavras e linhas com bastantes regressões. Em estágios mais avançados, a compreensão parece bem comprometida e são frequentes as viradas de página ou oscilações de linhas, bem como o entendimento de outro conteúdo da leitura. Frequentemente, se perdem na leitura 


\section{Revista do SELL \\ v. $4, n^{\circ} .1$ \\ ISSN: $1983-3873$}

e parecem se esquecer do que estavam fazendo. Como resultado, temos uma leitura fragmentada e meramente mecânica, uma vez que a compreensão já é quase inexistente.

Um outro ponto a destacar é a lentidão da leitura. Embora "a leitura não possa ser melhorada pela aceleração do globo ocular", como aponta Smith (2003, p.101), existe um limite com o qual o cérebro trabalha para extrair sentido da informação visual. Linguisticamente, diríamos produzir sentido por meio do conteúdo visual "captado" pela sensação. Para o autor, a lentidão pode comprometer a compreensão. Nesse contexto, a leitura deve ser fluida, nem lenta, nem rápida em demasia, mas no limite em que o cérebro seja capaz de interpretar.

$\mathrm{Na}$ lentidão, as palavras tendem a ser lidas de forma isolada. Em nosso estudo, verificamos que lentidão, de fato, atrapalha a compreensão, já que a noção de sequenciação fica prejudicada e com a memória comprometida. Em alguns momentos, presenciamos a virada de página no meio da leitura, sugerindo uma certa influência do comprometimento da memória no ato da leitura. Em geral, sabemos ser comum 0 abandono ou desistência do texto, seja por saturação da informação, desinteresse, cansaço, falta de entendimento, busca por nova informação ou qualquer outro motivo. No entanto, perguntamos aos participantes o motivo pelo qual estavam virando a folha e procurando por algo e a resposta normalmente correspondem a impressões como: "não sei, virei?"; "uai é para ler?", ou ainda, respondem coisas sem nexo, como "estou vendo se minha mãe está aqui".

A cada momento, informações chegam aos nossos sentidos e, no caso da leitura, não é diferente. É fato que o cérebro precisa extrair sentido dos conteúdos do que chega às vias sensoriais e utilizar o conhecimento já presente para extrair sentido da informação recebida. Vejamos, então, que a memória se encontra nesse intermédio entre "reter" de alguma forma o que vem dos sentidos, buscar o que já tem para, então, extrair uma conclusão. Nesse processo, uma operação de comparação entre o que chega e o que já é conhecido parece acontecer, haja vista nossa capacidade de reconhecer que algo já nos é conhecido.

Em outras palavras, a comparação parece um fenômeno natural pelo fato de termos a capacidade de nos lembrar e reconhecer a informação como já conhecida. Do contrário, a memória seria inútil e não reconheceríamos nada. Sendo assim, ao lermos algo, estamos lidando com as atuações da memória. "O que faz diferença na leitura é a efetividade do cérebro para utilizar o que já sabe (a informação não visual) para extrair 


\section{Revista do SELL}

v. $4, n^{\circ} .1$

ISSN: $1983-3873$

sentido da informação recebida (informação visual) mantida por curto espaço de tempo no armazenamento sensorial" (SMITH, 2003, p.114).

De outro modo, podemos dizer que a memória tem também um caráter de "guardar" o conteúdo lido para extrair sentido dos trechos e palavras subsequentes, pois, do contrário, seria complicado chegar ao final da leitura com qualquer noção do conteúdo. Porém, vale lembrar que não se trata puramente de um processo estocástico, mas de uma forma de extrair sentido a cada segmento. Se fosse pura estocagem ou acúmulo de informações, esbarraríamos na questão da limitação ou sobrecarga da memória, haja vista que conseguimos ler e compreender um texto, ainda que de grande extensão. A nosso ver, a memória de curto termo tem um papel relevante para a leitura, pois atua no sentido de reter o mínimo em pouco tempo para que a mente efetue o processamento do sentido. Em nosso estudo, observamos, de um modo geral, que a maior dificuldade pelos sujeitos com DA é na produção de sentido. A leitura automática ou mecânica foi observada em quase todos os estágios da DA, regredindo-se a cada fase.

\section{METODOLOGIA}

A análise deste estudo centrou-se num quadro metodológico de uma pesquisa de campo, de ordem qualitativa e de cunho exploratório, em instituições de longa permanência e residências particulares de idosos com DA (doença de Alzheimer). Para isso, foram selecionados 57 idosos, dividindo-os em grupos de mesma faixa etária, escolaridade e nível socioeconômico mais ou menos homegêneo. Como técnica de pesquisa, baseamo-nos numa observação direta participante, entrevista semiestruturada com registro em áudio. $O$ efeito priming foi observado a partir da leitura oral dos sujeitos observados e sua amostra selecionada para a análise da atuação desse efeito num viés lingüístico-discursivo. Como, em geral, nos casos de DA, as alterações da linguagem, principalmente, na leitura oral, só são possíveis de serem observadas em estágios mais avançados, procuramos selecionar os casos de DA, respeitando a Clinical Demential Rating $^{2}$, orientando-nos sobre os parâmetros dos níveis CRD 2 e CDR 3. Os sujeitos participantes deste estudo foram identificados por três letras.

2 Clinical Demential Rating consite em uma classificação desenvolvida no Projeto Memória e Envelhecimento na escola de Medicina da Universidade de Washington em 1979 para avaliação da gravidade da demência. Essa escala foi desenvolvida, principalmente, para uso em pessoas com demência de Alzheimer e é utilizada em todo o mundo. Sua classificação se divide em estágios: CDR 1 - perda de memória; ansiedade; agitação; ilusão; desconfiança; alteração da personalidade e do senso crítico; 


\section{ANÁLISE DA ATUAÇÃO DO EFEITO PRIMING PARA ESTIMULAÇÃO COGNITIVA: ANÁLISE LINGUÍSTICO-DISCURSIVA DO EFEITO PRIMING NA LEITURA ORAL DE IDOSOS COM DOENÇA DE ALZHEIMER}

É sabido que efeito priming consiste em um fenômeno de caráter cognitivo capaz de ajudar na evocação da linguagem em pacientes que tenham alguma dificuldade de expressar a linguagem. Sendo assim, trata-se de um recurso bastante empregado na tentativa de estimular ou fazer o paciente se lembrar do nome de algum termo linguístico, durante a interação. Nesse aspecto, a relação é de ativação da memória por meio de dicas silábicas, acreditando-se que o paciente completará o restante. Normalmente, esse fenômeno é também conhecido como estimulação. Na prática, ele pode ser usado para lembrar do termo a partir da mostra de um objeto ou imagem.

Como na DA, a dificuldade de encontrar palavras traz certo desconforto e sofrimento para o portador dessa patologia, tentamos verificar qual seria a atuação do efeito priming nas práticas interativas de leitura com esses sujeitos, além de analisar a influência da memória nas práticas de leitura. Dessa sorte, na tentativa de averiguar a atuação do efeito priming como estimulação cognitiva na leitura oral de idosos com DA, partimos para uma investigação, em que os sujeitos participantes tentassem ler frases e períodos curtos e longos. Na primeira interação, os participantes foram: DAL, sexo feminino, idade 78 anos, portadora de DA em nível CDR 3 e JAG, sexo feminino, 85 anos, portadora de DA, em nível CDR 2. No nível CDR 1 não verificamos a atuação do efeito priming na leitura, pelo fato de nesse estágio, a DA não compromete ativamente a leitura. A primeira participante foi submetida a uma tentativa de leitura da oração "A vida é uma jornada", sendo esta exposta em tipo e tamanho de fonte adequado, ambiente tranquilo e com boas condições de iluminação.

dificuldades com as AVD's; CDR 2 - dificuldade em reconhecer parentes e amigos; perder em ambientes conhecidos; alucinações; inapetência; perda de peso; incontinência urinária; dificuldades com a fala e comunicação; movimentos e fala repetitiva; distúrbios do sono; problemas com ações rotineiras; dependência progressiva; dispersão e dificuldades motoras; CDR 3 - Dependência total; imobilidade crescente; incontinência urinária e fecal; tendência em assumir posição fetal; mutismo; restrito à poltrona ou ao leito; presença de úlceras; perda progressiva de peso; infecções; término da comunicação; IV Agravamento dos sintomas da fase final; incontinência dupla; restrito ao leito; posição fetal; alimentação enteral; infecções e morte. 
Revista do SELL

v. $4, n^{\circ} .1$

ISSN: $1983-3873$

\begin{tabular}{|c|c|c|c|c|c|c|}
\hline Sujeito & DAL & Sexo & $\mathrm{F}$ & & Idade & 78 \\
\hline Escolaridade & \multicolumn{6}{|c|}{ Primário completo } \\
\hline Caracterização & \multicolumn{6}{|c|}{ Portador de DA em CDR-3 } \\
\hline Participantes & Portadora DA & JAG & Sexo & $\mathrm{F}$ & Idade & 85 \\
\hline Escolaridade & \multicolumn{6}{|c|}{ Primário incompleto } \\
\hline Caracterização & \multicolumn{6}{|c|}{ Portador de DA em CDR-2 } \\
\hline & Observadora & PCD & & & & \\
\hline Oração Original & \multicolumn{6}{|c|}{ A VIDA E UMA JORNADA } \\
\hline
\end{tabular}

\begin{tabular}{|c|l|l|l|l|l|l|}
\hline$L n$ & Locutor & \multicolumn{1}{|c|}{ Falas } & Ln & Locutor & \multicolumn{1}{|c|}{ Falas } \\
\hline 01 & DAL & A vida? & 02 & DAL & $\begin{array}{l}\text { A vida (Pausa) e esse "e" } \\
\text { aqui?: }\end{array}$ \\
\hline 03 & JAG & $\begin{array}{l}\text { Não dô. Essas letras não } \\
\text { dão }\end{array}$ \\
\hline $\begin{array}{l}\text { Intervenção é uma jornada } \\
\text { idosa, também portadora } \\
\text { de DA, em estágio menos } \\
\text { avançado que DAL) }\end{array}$ & 04 & DAL & & \\
\hline
\end{tabular}

Fonte: Dados da autora

Nessa primeira interação, a tentativa de DAL é de ler a oração " $A$ vida é uma jornada". Durante a atividade, observamos que a idosa consegue apenas pronunciar o início da oração 02: "A vida...", estranhando o restante das palavras, mesmo com a intervenção de JAG, na linha 03 “Ao/ $A$ vida é uma jornada”, pelas expressões 04: "Não dô. Essas letras não dão". Verificamos que, nesse caso, DAL demonstra dificuldade na descodificação das palavras. A hipótese para esse fenômeno é a possibilidade de falha de memória afetando a linguagem, no sentido de não se lembrar da pronúncia das palavras, uma vez que demonstra não saber a palavra resultante da formação das letras, ao dizer "[...] essas letras não dão". Nesse caso, por mais que JAG tenha dito a oração para DAL, isso não surtiu como efeito priming, auxiliando-a no reconhecimento da oração. Nesse sentido, foi possível confirmar que o priming consiste realmente num fenômeno de sílabas e não de frases ou orações completas. Num segundo momento, uma outra tentativa de leitura foi realizada com a mesma participante DAL, foi possível observar mais claramente o efeito priming, a partir da estimulação das primeiras sílabas da palavra.

\begin{tabular}{|c|c|c|c|c|c|c|}
\hline Sujeito & DAL & Sexo & $\mathrm{F}$ & & Idade & 78 \\
\hline Escolaridade & \multicolumn{6}{|c|}{ Primário completo } \\
\hline Caracterização & \multicolumn{6}{|c|}{ Portador de DA em CDR-3 } \\
\hline Participantes & Portadora DA & JAG & Sexo & $\mathrm{F}$ & Idade & 85 \\
\hline Escolaridade & \multicolumn{6}{|c|}{ Primário incompleto } \\
\hline Caracterização & \multicolumn{6}{|c|}{ Portador de DA em CDR-2 } \\
\hline & Observadora & PCD & & & & \\
\hline Oração original & \multicolumn{6}{|c|}{ A ESTRADA DA VIDA } \\
\hline
\end{tabular}


Revista do SELL

v. $4, n^{\circ} .1$

ISSN: $1983-3873$

\begin{tabular}{|c|c|c|c|c|c|}
\hline Ln & Locutor & Falas & Ln & Locutor & Falas \\
\hline 01 & DAL & A é essa te (Pausa) & 02 & PCD & A estra...? \\
\hline 03 & DAL & Estrada? & 04 & PCD & Isso \\
\hline 05 & DAL & Que mais? & 06 & PCD & O que está escrito aqui? \\
\hline 07 & DAL & Aqui? & 08 & PCD & E \\
\hline 09 & DAL & $\begin{array}{l}\text { Não tem nada. que de } \\
\text { derer aqui prá cá. Ah não } \\
\text { tem esse que chega aqui. } \\
\text { A/A: Estra }\end{array}$ & 10 & PCD & A estrada \\
\hline 11 & DAL & $\begin{array}{l}\text { estão sa/sa/saldadas dada } \\
\text { quando dá na vida a vida } \\
\text { virá será. Não é isso? }\end{array}$ & & & \\
\hline
\end{tabular}

Fonte: Dados da autora

Nessa interação, podemos observar que DAL inicia a leitura oral do trecho " $A$ estrada da vida" já com bastante dificuldade de descodificação. Vale apontar que a idosa começa a leitura como se estivesse lendo ou reconhecendo letras isoladas e somente inicia uma silabação após a nossa intervenção, a partir de efeito priming. Nesse caso, verificamos que ainda assim, o efeito só foi válido para a primeira palavra do trecho e o restante foi marcado por estranha construção em 11: "estão sa/sa/saldadas dada quando dá na vida a vida virá será. Não é isso?". Nesse caso, não sabemos, porém, se se trata de uma agramaticalidade ou repetição da sílaba "da", no caso de "sa/sa/saldadas dada quando dá na vida" ou uma tentativa de correção da palavra em "virá será", pois, em geral, não constatamos agramaticalidade nas falas dos idosos com DA.

Em 09: "Não tem nada. que de derer aqui prá cá. Ah não tem esse que chega aqui. A/A: Estra...", observamos que DAL não consegue dar sequência à descodificação da frase, dizendo não haver nada escrito ali. No trecho "[...] que de derer aqui prá cá”, é bem possível que a intenção fosse dizer "Não tem nada daqui para cá", ou, em outras palavras, "Não não tem mais nada para ser lido do ponto " $A$ estrada..." .Contudo, não se trata de um problema de visão, uma vez que tentou ler outras frases e palavras além de pronunciar o início da frase. Isso nos leva a crer que o comprometimento de memória de DAL tenha influenciado a "leitura" do restante da frase.

Na linha 11, após termos reforçado qual seria o início da frase, em 10: " $A$ estrada", observamos que o trecho "da vida" apareça, talvez, como uma tentativa entremeado ao emaranhado de palavras desconexas em "estão sa/sa/saldadas dada quando dá na vida a vida virá será. Não é isso?" O mesmo acontece com MMX, 85 anos, sexo feminino, 


\section{Revista do SELL \\ v. $4, n^{\circ} .1$ \\ ISSN: $1983-3873$}

portadora de DA, em estágio avançado, primário completo, que ao, "ler" a oração " $A$ vida é uma jornada”, pronunciou também algo semelhante, no que diz respeito à repetição de sílabas e à modificação do restante do trecho original: "Vida vidadadadadada é muito boa". Nesse sentido, acreditamos que a falha mnemônica tenha sido o fator causal para a "leitura" oral, sugerindo certa influência da memória na leitura.

Na DA, o esquecimento é um dos fatores mais perceptíveis. Durante a leitura, vimos que os idosos com DA cometem algumas pausas, dependendo do estágio da doença além de muita dispersão, o que compromete uma distinção precisa do que se refere ao fator atencional e mnemônico. Contudo, ao analisarmos a leitura de JCS, 71 anos, sexo masculino, portador de DA, primário completo, verificamos que, muitas vezes, ao longo da leitura era preciso estimulá-lo e lembrá-lo da tarefa. Na maioria das vezes, a dispersão centrava-se na fixação do olhar sobre o texto, parecendo certo devaneio e esquecimento sobre o que estava fazendo. Vimos, portanto, que atenção e memória estão imbricadas, uma vez que JCS precisava ter atenção sobre a ação que estava realizando, ao mesmo tempo em que era preciso ter em mente ou se lembrar da tarefa, haja vista que a atividade de leitura requer certa sequencialidade. Sobre esse aspecto, observamos também que, mesmo seguindo as linhas com os dedos, JCS se perdia na leitura, algumas vezes, esquecendo-se de dar sequência à leitura. Seguem abaixo o texto lido e a respectiva interação, a partir da leitura de JCS.

\section{As três árvores}

\section{O sonho não é nada perto da realização}

Havia, no alto da montanha, três pequenas árvores que sonhavam o que seriam depois de grandes. A primeira, olhando para as estrelas, disse:- Quero ser o baú mais preciso do mundo, cheio de tesouros. Para tal, até me disponho a ser cortada.

A segunda olhou para o riacho e suspirou:- Quero ser um grande navio para transportar reis e rainhas. A terceira árvore olhou o vale e disse:-Quero ficar aqui no alto da montanha e crescer tanto que as pessoas, ao olharem para mim, levantem os olhos e pensem em Deus.

Muitos anos se passaram e, certo dia, vieram três lenhadores e cortaram as três árvores ansiosas para ser transformadas naquilo com que sonhavam. A primeira árvore acabou sendo transformada num cocho de animais coberto de feno. A segunda virou um simples e pequeno barco de pescam carregando pessoas e peixes todos os dias. E a terceira, mesmo sonhando em ficar no alto da montanha, acabou cortada em altas vigas e colocada de lado em um depósito. E todas as três se perguntavam, desiludidas e tristes:- Para que isso?Mas, certa noite, cheia de luz e estrelas, com mil melodias no ar, uma jovem mulher 


\section{Revista do SELL \\ v. $4, n^{\circ} .1$}

ISSN: $1983-3873$

colocou seu bebê recém-nascido naquele cocho de animais. De repente, a primeira árvore percebeu que nela repousava o maior tesouro do mundo.

A segunda árvore, anos mais tarde, transportou um homem que acabou dormindo no barco, mas, quando a tempestade quase afundou o pequeno barco, o homem se levantou e disse: "paz"! E num relance, a segunda árvore entendeu que estava carregando o rei dos céus e da terra. Tempos mais tarde, numa sexta-feira, a terceira árvore espantou-se quando suas vigas foram unidas em forma de cruz e um homem foi pregado nela. Logo, se sentiu horrível e cruel. Mas, logo no domingo, o mundo vibrou de alegria, e a terceira árvore entendeu que nela havia sido pregado o homem que veio salvar a humanidade e que as pessoas sempre se lembrariam de Jesus Cristo ao olhar para ela. As árvores sonharam, mas a realização foi mil vezes melhor do que haviam imaginado.

\begin{tabular}{|c|c|c|c|c|c|}
\hline Sujeito & JCS & Sexo & M & Idade & 71 \\
\hline Escolaridade & \multicolumn{5}{|c|}{ Primário completo } \\
\hline Caracterização & \multicolumn{5}{|c|}{ Portador de DA em CDR-2 } \\
\hline & Observadora & PCD & & & \\
\hline
\end{tabular}

\begin{tabular}{|c|c|c|c|c|c|}
\hline $\mathrm{Ln}$ & Locutor & Falas & Ln & Locutor & Falas \\
\hline 01 & PCD & O sonho..? & 02 & JCS & $\begin{array}{l}\text { O sonho... não é nada perto da } \\
\text { rea }(\text { ) }\end{array}$ \\
\hline 03 & PCD & $\begin{array}{l}\text { Realização! Isso mesmo! } \\
\text { Vamos lá! }\end{array}$ & 04 & PCD & Havia...? \\
\hline 05 & JCS & $\begin{array}{l}\text { No alto da montanha } \\
\text { (pausa) }\end{array}$ & 06 & PCD & Três...? \\
\hline 07 & PCD & $\begin{array}{l}\text { Olha aqui oh três...? } 0 \\
\text { que? }\end{array}$ & 08 & JCS & $\begin{array}{l}\text { Pequ ( ) árvores sonhavam } \\
\text { (pausa) }\end{array}$ \\
\hline 09 & PCD & Sonhavam...? & 10 & JCS & Hum \\
\hline 11 & PCD & Sonhavam...? & 12 & JCS & O quê? \\
\hline 13 & JCS & Bom... & 13 & PCD & Sonhavam o que...? \\
\hline 14 & JCS & $\begin{array}{l}\text { Queriam depois de veia. A } \\
\text { primeirar olhando } \\
\text { prasestrela disse: quero } \\
\text { ser o bau mais preciso do } \\
\text { mundo cheios( }) \text { tesoros } \\
\text { (pausa) }\end{array}$ & 15 & PCD & Para tal...? \\
\hline 16 & JCS & 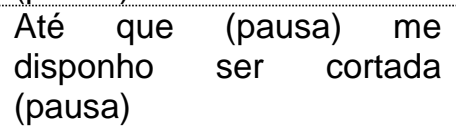 & 17 & PCD & E aí? \\
\hline 18 & JCS & $\begin{array}{l}\text { A seguida olhou para o } \\
\text { riacho e suspirou (pausa) } \\
\text { Quero ser um grande navio } \\
\text { para transportar reis e } \\
\text { rainhas. (pausa) }\end{array}$ & 19 & PCD & E aí? \\
\hline 20 & JCS & $\begin{array}{l}\text { A terceira olhou o ba/vale e } \\
\text { disse: quero ficar aqui no } \\
\text { alto da montanha e crescer } \\
\text { tanto que as pessoas ao } \\
\text { olharem para mim levantei/ } \\
\text { levantem os olhos e } \\
\text { pensem em Deus }\end{array}$ & 21 & PCD & E o resto? \\
\hline 22 & JCS & $\begin{array}{l}\text { Muitos anos se passaram e } \\
\text { certo dia vieram três }\end{array}$ & 23 & PCD & Naquilo com que...? \\
\hline
\end{tabular}


Revista do SELL

v. $4, n^{\circ} .1$

ISSN: $1983-3873$

\begin{tabular}{|c|c|c|c|c|c|}
\hline $\operatorname{Ln}$ & Locutor & Falas & $\operatorname{Ln}$ & Locutor & Falas \\
\hline & & $\begin{array}{l}\text { (pausa) lenhadores e } \\
\text { cortaram as seis álvores } \\
\text { ansioso para ser } \\
\text { transformadas naquilo com } \\
\text { que (desses) ( ) }\end{array}$ & & & \\
\hline 24 & JCS & $\begin{array}{l}\text { Sonhavam } \\
\text { acabou? }\end{array}$ & 25 & PCD & A primeira árvore... acabou? \\
\hline 26 & JCS & $\begin{array}{l}\text { Sendo transformada co/co/ } \\
\text { cocho dedeanimais coberto } \\
\text { de ferro (pausa) }\end{array}$ & 27 & PCD & A segunda....? \\
\hline 28 & JCS & $\begin{array}{l}\text { Virou um simples e } \\
\text { pequeno barco de pesca } \\
\text {...carregando pessoas e } \\
\text { peixes todos os dias. E a } \\
\text { terceira mesmo } \\
\text { sonh/sonhando e/em ficar } \\
\text { no alto ...da montanha } \\
\text { acabou cortada em altas } \\
\text { vi:/vigas e colocada de lado } \\
\text { em um depósito. E todas } \\
\text { as três perguntavam } \\
\text { desisiludidas e triste para } \\
\text { que isso? Certa noite cheia } \\
\text { de luz e estrelas com mil } \\
\text { melodias no ar uma } \\
\text { Jó/uma jovem mulher } \\
\text { colocou seu bebê nascido } \\
\text { (pausa) no... cocho de } \\
\text { animais }\end{array}$ & 29 & PCD & De repente...? \\
\hline 30 & JCS & Um & 31 & PCD & $\begin{array}{l}\text { De repente? (Pausa) De } \\
\text { repente a primeira....? }\end{array}$ \\
\hline 32 & JCS & $\begin{array}{l}\text { Árvore percebeu que nela } \\
\text { repousava o maior tesouro } \\
\text { do mundo }\end{array}$ & 32 & PCD & O que mais? \\
\hline 33 & JCS & Só! & 34 & PCD & A Segunda árvore....? \\
\hline 35 & JCS & 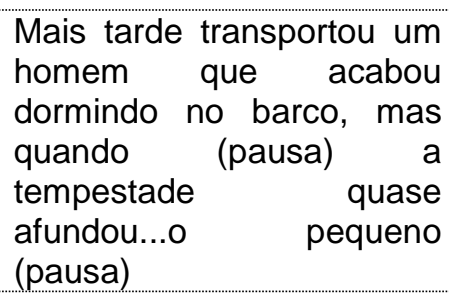 & 35 & PCD & Cansou? Acabou? \\
\hline 36 & JCS & Acabou & 37 & PCD & Acabou a história? \\
\hline
\end{tabular}

No início de cada texto, era preciso ler a primeira palavra integralmente ou ainda as primeiras sílabas para JCS para que ele conseguisse seguir o restante. Porém, sempre apontando para as palavras do texto, para que JCS não se dispersasse. Sem o estímulo, JCS não seguia as linhas com os dedos, nem prosseguia com a "leitura" de todo o texto, deixando-o nos primeiros parágrafos. Nesse caso, vimos que seguir as linhas com os dedos ajudava-o, de alguma forma, a manter-se na "leitura", ainda que com relativas 


\section{Revista do SELL \\ v. $4, n^{\circ} .1$ \\ ISSN: $1983-3873$}

pausas. Nesse caso, observamos que o efeito priming contribuía para que o sujeito mantivesse a interação e desse sequência à leitura.

$\mathrm{Na}$ leitura silenciosa, observamos que JCS não conseguia seguir a leitura sozinho e não soube nos dizer o que "leu" quando perguntamos a ele sobre o quê o texto tratava, isto é, o assunto. Nesse caso, vimos que a leitura silenciosa requer ainda mais desses sujeitos atenção e memória. Tudo indica que o elemento sonoro da leitura oral ajuda-os um pouco mais na atividade de leitura. Nessa interação, observamos que, constantemente, era necessário dar um estímulo inicial para que JCS iniciasse a leitura oral, o que nos levou a crer que o efeito priming, nesse caso, desencadeava o restante da leitura. Em várias passagens, as pausas também eram frequentes, muitas vezes, deixando a leitura de um trecho inacabada. Foi preciso, na linha 29: “De repente...?', por exemplo, dar um novo estímulo lendo as primeiras palavras para que JCS continuasse a leitura 30: "um" e 32: "Árvore percebeu que nela repousava o maior tesouro do mundo". $\mathrm{Na}$ linha 30, percebemos certa tentativa de continuar a leitura do restante da frase, contudo, JCS designou "um" no lugar de "a primeira", depois de certo esforço e por meio do estímulo 31: "De repente? (Pausa) De repente a primeira...?" para que o fizesse voltar à sequência da leitura, levando-nos a crer que tenha ocorrido algum lapso mnemônico e atencional. A partir da linha 08: "Pequ () árvores sonhavam (pausa)", em que JCS interrompe a "leitura", vimos que, mesmo tentando um estímulo por meio da repetição da palavra do trecho interrompido 09 e 11: "Sonhavam...?", JCS demonstra não se lembrar da realização da leitura do texto 12: "O quê"?. Somente após outro estímulo 13: "Sonhavam o que...?", contendo a palavra com a qual o termo que está ligado no texto, no trecho original "[...] Havia no alto da montanha, três pequenas árvores que sonhavam o que seriam depois de grandes", que JCS deu sequência à leitura. Isso nos mostra, em outras palavras, além da desatenção, certa "falha" de memória, por não se lembrar do que estava fazendo. Em 14: "Queriam depois de veia. A primeira olhando prasestrela disse: quero ser o baú mais preciso do mundo cheios( )tesoros (pausa)", as trocas no trecho "Queriam depois de veia [...]", no lugar da versão original "[...]seriam depois de grandes" revelam também lapsos de linguagem de atenção, principalmente no termo "queriam" em vez "seriam", em que a troca pode ser verificada no plano do fonema, e de memória, principalmente que a troca de "grandes" por "véia" induz a uma interpretação, em razão do significado de "crescidas", remetendo a "velhas". Nesse caso, tudo indica que JCS tenha estabelecido a relação entre esses termos. Contudo, na interpretação geral do 


\section{Revista do SELL}

v. $4, n^{\circ} .1$

ISSN: $1983-3873$

texto, JCS afirma não se lembrar de nada do texto "lido". Sob esse aspecto, é possível que a informação tenha se perdido ao longo da "leitura".

A maioria das memórias é perdida ao longo do tempo por não mais ativar as sinapses que a carregavam. A este respeito, Edelman (1998) também aponta a mesma sugestão: a de que as memórias formam "caminho" ou "trilhas" neuronais específicas e que estas são posteriormente reconhecidas a cada momento da lembrança. Nesse aspecto, o desuso é para Izquierdo (2005) o caráter fundamental para o esquecimento.

Izquierdo (2005) revela que a única forma de ser preservar as memórias é estimulando-as e destaca que a atividade de leitura é um ótimo exercício por envolver uma série de regiões cerebrais e ativar várias memórias como a visual, verbal, imagens e motoras. Sobre a DA, o autor nos lembra que, de modo geral, indivíduos com mais escolaridade tendem a sofrer menos no sentido de chegar às últimas fases da doença $e$ recomenda a leitura como um exercício cognitivo.

\section{DISCUSSÃO E RESULTADOS}

A partir da observação direta da leitura dos idosos com DA, verificamos que tudo leva a crer que o processo mnemônico reúne elementos isolados para associá-los entre si. Afinal, pelo recall, foi possível perceber que alguns elementos servem de "gatilho" para a associação e evocação de imagens mentais da memória. Nesse aspecto, verificamos o fato de que o processo de interpretação parte do conhecimento das partes que a compõem. A leitura consiste, nesse sentido, num processo interativo, no qual a interação contribui para o processo de produção de sentido. Isso pode ser mais bem avaliado quando observamos a interação com o idoso com DA para que este conseguisse fazer a "leitura" de textos e na interação entre os próprios idosos. Também por meio de estímulos, foi possível observar que a memória pode ser vista como uma operação mental de interdiscurso, uma vez que a cada recall, é possível entender a associação com um novo discurso. Nesse aspecto, vimos ainda que, apesar de todas as controvérsias em torno da capacidade de estocagem da memória, é bem provável que alguma parte fique registrada na memória, haja vista que durante o recall, acontece o reconhecimento. Em geral, o efeito priming tem efeito positivo como estímulo para o recall até certo estágio da DA, uma vez que o fenômeno serve como ativação dos mecanismos mnemônicos, sendo 


\section{Revista do SELL \\ v. $4, n^{\circ} .1$ \\ ISSN: $1983-3873$}

possível observar como resultado uma seqüencialidade da leitura, ainda que restrita em função dado agravamento da doença.

\section{CONSIDERAÇÕES FINAIS}

A partir da análise das interações e das tentativas de leitura de idosos com e sem DA, foi possível confirmar a hipótese de uma correlação entre memória, linguagem e leitura. Observamos, nesse sentido, certa influência da memória na linguagem, ao avaliarmos as várias "trocas" e truncamentos de termos, tanto na interação dialógica, quanto na atividade de leitura. Ademais, o comprometimento mnemônico revelou interrelação com lapso de atenção, interferindo, assim, na leitura efetiva de textos. Partimos do postulado de que a leitura envolve compreensão / entendimento. Com efeito, verificamos que o nível de compreensão é inversamente proporcional ao estágio da DA, ou seja, quanto maior o estágio de DA, menor é o nível de compreensão de linguagem, haja vista os estudos realizados para análise, tanto da conversação, quanto da leitura desses sujeitos. Confirmamos a hipótese de que os idosos com DA "leem" de forma mecânica, pois acabam refletindo uma interpretação vazia de sentido, ou ainda, ao silêncio, revelando influência tanto da memória, quanto da atenção no processo de leitura. Afinal, atenção e memória resultam em termos imbricados, já que verificamos a influência da atenção tanto para a memorização ou registro da informação, quanto para o processo de recall, em que focalizamos a atenção sobre algo, a fim de trazer à tona da memória a informação.

No processo de interação e na produção discursiva, compreendemos que, na tentativa de leitura dos sujeitos com DA em nosso estudo, a interação contribui para a produção de sentido, permitindo-Ihes certo estímulo para a memória. Nesse contexto, verificamos que o efeito priming é também válido para a atividade de leitura mecânica, pois a partir do momento em que iniciávamos as primeiras palavras do texto, o idoso tentava dar a sequência à "leitura". Todavia, nos estágios avançados da DA, vimos que o efeito priming tende a decair, em função do agravamento das funções mnemônicas. De fato, vimos que o nível da DA afeta sobremaneira a linguagem e, consequentemente, a leitura, pois em fases mais avançadas muitos são os comprometimentos cognitivos.

Foi possível corroborar a ideia de que há certa influência da memória no processo da leitura, porquanto verificamos significativas alterações de linguagem e dificuldades de 
leitura entre os sujeitos com DA, em comparação a indivíduos normais. A atuação do efeito priming, sugere, nesse caso, portanto, uma forma de ativação da memória, levandonos a crer que, ainda com o comprometimento, alguma informação mínima esteja presente, pois, do contrário, a evocação não seria possível.

\section{REFERÊNCIAS}

BUTLER, Laurie T; BERRY, Dianne C. Understanding the relationship between repetition priming and mere exposure. British Journal of Psichology (95). P.467-487, 2004.

CAYTON, Harry; WARNER, James; GRAHAM, Nori. Tudo sobre a doença de Alzheimer. Trad. José Ricardo Amaral de Souza Cruz. São Paulo: Andrei, 2000.

CHARTIER, Anne-Marie. A leitura e sua aprendizagem. In: MARI, H; WALTY, I;VERSIANI, Z. Ensaios sobre leitura. Belo Horizonte: PUC Minas, 2005, p.47-67.

CHARTIER, Roger. Forms and meanings: texts, performances and audiences from codex to computer. USA: University Pennsylvania Press, 1995.

CORRÊA, Antônio Carlos de Oliveira. Memória, aprendizagem e esquecimento: a memória através das neurociências cognitivas. São Paulo: Atheneu, 2010.

FISCHER, Steven R. História da Leitura. Trad. Claudia Freire. São Paulo: UNESP, 2006.

FLEISCHMAN, Debra A; GABRIELI, John D.E; REMINGER, Sheryl.L;VAIDYA, Chandan J; BENNETT, David A. Object decision priming in Alzheimer's disease. Journal of the International Neuropsychological Society 4, 435-446, 1998.

FRITH, U. Reading by eye and writing by ear. In: KOLERS, P. A.;WROLSTAD, M. E.; BOUMA, H. (Eds.) Processing of Visible Language. Nova York, 1979, p. 379-390.

HUDMON, Andy. Learning and memory. Yale University Department of Neurology. New York: Chelsea House, 2006

IZQUIERDO, Ivan. Memória. Porto Alegre: Artmed, 2002.

KLEIMAN,Ângela.Oficina de Leitura. Campinas:Pontes, 1995a

KLEIMAN,Ângela.Texto e leitor.4ª ed. Campinas:Pontes, 1995b

MARI, H; MENDES, P.A. Processos de leitura: fator textual.In: In: MARI, H;WALTY, I;VERSIANI, Z. Ensaios sobre leitura. Belo Horizonte: PUC Minas, 2005, p.155-180.

SCHOPENHAUER, Arthur. Sobre a visão e as cores. Trad. Erlon José Paschoal. São Paulo: Nova Alexandria, 2003. 


\section{Revista do SELL}

v. $4, n^{\circ} .1$

ISSN: $1983-3873$

SMITH, Frank. Compreendendo a leitura: uma análise psicolinguística da leitura e do aprender a ler. Trad. Daise Batista. Porto Alegre: Artes Médicas, 2003. 